\title{
Documento: Pornografía y Violencia en las Comunicaciones Sociales Una respuesta pastoral
}

Durante el último año el Consejo Pontificio para las Comunicaciones Sociales dio a conocer el documento Pornografía y Violencia en las Comunicaciones Sociales. Una respuesta pastoral (Ciudad del Vaticano, 7 de mayo de 1989). Se trata de una interpelación dirigida en parte importante aunque no exclusiva a los informadores católicos y que merece, de parte de éstos, no sólo una buena voluntad general en el sentido de seguir sus orientaciones, sino un intento de entender críticamente, si es necesario, su visión del problema. A continuación entregamos el texto completo y enseguida un comentario preparado por el profesor Jaime Martínez Williams.

\section{Introducción}

1. En el curso de estos últimos años ha tenido lugar una revolución mundial en el modo de percibir los valores morales, seguida de cambios profundos en la manera de pensar y actuar de la gente. Los medios de comunicación social han tenido y continúan teniendo un importante papel en este proceso de transformación individual y social, en la medida que introducen y reflejan nuevas actitudes y estilos de vida.'

2. Algunos de estos cambios han resultado positivos. Hoy, como ha afirmado recientemente el Papa Juan Pablo II, «la primera nota positiva consiste en que muchos hombres y mujeres tienen plena conciencia de su dignidad y de la de todo ser humano... Al propio tiempo, en un mundo dividido y trastornado por conflictos de todo tipo, va creciendo la convicción de una interdependencia radical $y$, por consiguiente, la necesidad de una solidaridad que la asuma y la traduzca en el plano moral»². Las comunicaciones sociales han contribuido mucho a que se den estos cambios.

3. Pero muchos de estos cambios han sido negativos. Al lado de los abusos de siempre se están dando nuevas violaciones de la dignidad humana y de los valores e ideales cristianos. $Y$ aquí también las comunicaciones sociales tienen su parte de responsabilidad. 
4. Si bien es cierto que estos medios - como afirma el Concilio Vaticano II- «prestan grandes servicios al género humano», lo es igualmente que "pueden ser utilizados contra los designios del Creador y convertidos en instrumentos del mal». ${ }^{3}$

5. Uno de los fenómenos alarmantes de estos años ha sido la creciente difusión de la pornografía y la generalización de la violencia en los medios de comunicación social. Libros y revistas, cine y teatro, televisión y videocassettes, espacios publicitarios y las propias telecomunicaciones, muestran frecuentemente comportamientos violentos o de sexualidad permisiva que casi llegan al umbral de la pornografía y que son moralmente inaceptables.

6. La pornografía y la exaltación de la violencia son viejas realidades de la condición humana que evidencian la componente más turbia de la naturaleza humana, dañada por el pecado. Durante el último cuarto de siglo han adquirido una amplitud nueva y han pasado a constituir un serio problema social. Mientras crece la confusión respecto de las normas morales, las comunicaciones han hecho la pornografía y la violencia accesibles al gran público, incluidos niños y jóvenes. Este problema, que quedaba confinado antes en el ámbito de los países ricos, ha comenzado, con la comunicación moderna, a corromper los valores morales de las naciones en vías de desarrollo.

7. Los medios de comunicación social pueden ser a la vez eficaces instrumentos de unidad y comprensión mutua y trasmisores de una visión deformada de la vida, de la familia, de la religión y de la moralidad -según una interpretación que no respeta la auténtica dignidad ni el destino de la persona humana- ${ }^{4}$. En particular, los responsables familiares de muchas regiones del mundo han expresado una comprensible preocupación respecto de los filmes, videocassettes y programas de televisión que sus hijos están en condiciones de ver, así como grabaciones que pueden oír y publicaciones que pueden leer. Y se niegan a que los valores morales inculcados en el hogar queden destruidos por producciones rechazables, en todas partes de fácil acceso gracias a estos medios.

8. Se trata de ilustrar en este documento los efectos más graves de la pornografía y la violencia en el individuo y en la sociedad, así como señalar las causas principales del problema tal como se plantea hoy. Por último se tratará de indicar los pasos necesarios que han de dar los comunicadores profesionales, los padres y educadores, la juventud y el público en general, las autoridades civiles y eclesiásticas, las organizaciones privadas y religiosas, para poner el remedio necesario.

\section{Efectos de la pornografía y la violencia}

9. La experiencia cotidiana confirma los estudios realizados en el mundo entero acerca de las consecuencias negativas de la pornografía y de las escenas de violencia que transmiten los medios de comunicación socials. Se entiende por pornografía, en este contexto, la violación, merced al uso de las técnicas audiovisuales, del derecho a la privacidad del cuerpo humano en su naturaleza masculina y femenina, una violación que reduce la persona humana y el cuerpo humano a un objeto anónimo destinado a una mal utilización con la intención de obtener una gratificación concupiscente. La violencia, en este contexto, puede ser entendida como la presentación destinada a excitar instintos humanos fundamentales hacia actos contrarios a la dignidad de la persona, y que describe una fuerza física intensa ejercida de manera profundamente ofensiva y a menudo pasional. Los especialistas a veces no están de acuerdo sobre el impacto de este fenómeno y sobre el modo en que afecta a los individuos y los grupos aquejados por el mismo, pero las líneas maestras de la cuestión aparecen claras, limpias e inquietantes.

10. Nadie puede considerarse inmune a los efectos degradantes de la pornografía y la violencia, o a salvo de la erosión causada por los que actúan bajo su influencia. Los niños y los jóvenes son especialmente vulnerables a ser víctimas. La pornografía y la violencia sádica deprecian la sexualidad, pervierten las relaciones humanas, explotan los individuos -especialmente las mujeres y los niños-, destruyen el matrimonio y la vida familiar, inspiran actitudes antisociales y debilitan la fibra moral de la sociedad.

11. Es evidente que uno de los efectos de la pornografía es el pecado. La participación voluntaria en la producción y en la difusión de estos productos nocivos ha de ser considerada como un serio mal moral. Además, esta producción y difusión no podrían tener lugar si no existiera una demanda. Así, pues, quienes hacen uso de estos productos no sólo se perjudican a sí mismos, sino que también contribuyen a la promoción de un comercio nefasto.

12. Una exposición frecuente de los niños a la violencia en las comunicaciones sociales puede resultar turbadora para ellos, al ser todavía incapaces de distinguir claramente la fantasía de la realidad.

Además, la violencia sádica en estos medios puede condicionar a las personas impresionables, sobre todo a los jóvenes, hasta el punto de que la lleguen a considerar normal, aceptable y digna de ser imitada. 
13. Se ha dicho que puede haber una vinculación psicológica entre la pornografía y la violencia sádica. Una cierta pornografía ya es abiertamente violenta en su contenido y expresión. Quienes ven, escuchan o leen un material así corren el riesgo de introducirlo en el propio comportamiento. Acaban perdiendo el respeto hacia los demás, en cuanto hijos de Dios y hermanos y hermanas de la misma familia humana. Una vinculación tal entre pornografía y violencia sádica tiene especiales implicaciones para quienes están afectados de ciertas enfermedades mentales.

14. También la llamada pornografía blanda ("soft core") puede paralizar progresivamente la sensibilidad, ahogando gradualmente el sentido moral de los individuos hasta el punto de hacerles moral y personalmente indiferentes a los derechos y a la dignidad de los demás.

La pornografía - como la droga- puede crear dependencia y empujar a la búsqueda de un material cada vez más excitante ( "hard core") y perverso. La probabilidad de adoptar comportamientos antisociales crecerá en la medida que se vaya dando este proceso.

15. La pornografía favorece insalubres preocupaciones en los terrenos de la imaginación y el comportamiento. Puede interferir en el desarrolo moral de la persona y en la maduración de las relaciones humanas sanas y adultas, especialmente en el matrimonio y en la familia, que exigen confianza recíproca y actitudes e intenciones de explícita integridad moral.

16. La pornografía, además, cuestiona el carácter familiar de la sexualidad humana auténtica. En la medida en que la sexualidad se considere como una búsqueda frenética del placer individual, más que como una expresión perdurable del amor en el matrimonio, la pornografía aparecerá como un factor capaz de minar la vida familiar en su totalidad.

17. En el peor de los casos, la pornografía puede actuar como agente de incitación o de reforzamiento, un cómplice indirecto, en agresiones sexuales graves y peligrosas, tales como la pedofilia, los secuestros y asesinatos.

18. Una de las consecuencias fundamentales de la pornografía y de la violencia es el menosprecio de los demás, al considerarles como objetos en vez de personas. La pornografía y la violencia suprimen la ternura y la compasión para dejar su espacio a la indiferencia, cuando no a la brutalidad.

\section{Causas del problema}

19. Uno de los motivos básicos de la difusión de la pornografía y de la violencia sádica, en el ámbito de los medios de comunicación, parece ser la propagación de una moral permisiva, basada en la búsqueda de la satisfacción individual a toda costa. Un nihilismo moral de la desesperación se añade a ello, que acaba haciendo del placer la sola felicidad accesible a la persona humana.

20. Un cierto número de causas más inmediatas contribuyen ulteriormente a la escalada de la pornografía y la violencia en los medios.

Entre éstas cabe citar:

-el beneficio económico. La pornografía es una industria lucrativa. Algunos sectores de la industria de las comunicaciones han sucumbido trágicamente a la tentación de explotar la debilidad humana, especialmente la de los jóvenes y la de las mentes impresionables, para obtener provecho de producciones pornográficas y violentas. Esta industria pornográfica, en algunas sociedades, resulta lucrativa hasta el punto de que se ha vinculado al crimen organizado;

-falsos argumentos libertarios. La libertad de expresión exige, según algunos, la tolerancia hacia la pornografía, aún al precio de la salud moral de los jóvenes y del derecho a la intimidad, así como un ambiente de pública decencia. Algunos, también erróneamente, afirman que el mejor medio de combatir la pornografía consiste en legalizarla. Estos argumentos son a veces propuestos por grupos minoritarios que no se suman a los criterios morales de la mayoría y que se olvidan de que a cada derecho corresponde una responsabilidad. El derecho a la libertad de expresión no es un absoluto. La responsabilidad pública de promover el bien moral de los jóvenes, de garantizar el respeto de las mujeres, de la vida privada y de la decencia pública muestra claramente que la libertad no puede equipararse al libertinaje;

- la ausencia de leyes cuidadosamente preparadas o su no aplicación, para la protección del bien común, en particular de la moralidad de los jóvenes;

-confusión y apatía por parte de muchos, incluso miembros de la comunidad religiosa, los cuales se consideran erróneamente a sí mismos extraños a la problemática de la pornografía y de la violencia en los medios, o sin posibilidades de contribuir a la solución del problema. 


\section{Respuestas al problema}

21. La propagación de la pornografía y de la violencia a través de los medios de comunicación social es una ofensa a los individuos y a la sociedad y plantea un problema urgente que exige respuestas realistas por parte de las personas y los grupos. El legítimo derecho a la libertad de expresión y al intercambio libre de información ha de ser protegido.

Al mismo tiempo, hay que salvaguardar el derecho de los individuos, de las familias y de la sociedad a la vida privada, a la decencia pública y a la protección de los valores esenciales de la vida.

22. Se hará referencia a siete sectores con especiales deberes en la materia: profesionales de la comunicación, padres, educadores, juventud, público en general, autoridades públicas e Iglesia y grupos religiosos.

23. Profesionales de la comunicación. Sería desleal sugerir que todos los medios y todos los comunicadores están implicados en este negocio nocivo. Son muchos los comunicadores que se distinguen por sus cualidades personales y profesionales. Tratan de asumir su responsabilidad aplicando con fidelidad las normas morales y les anima un gran deseo de servicio al bien común. Se merecen nuestra admiración y estímulo, especialmente los que se dedican a la creación de sanos esparcimientos familiares.

Se invita encarecidamente a estos comunicadores a unirse para la elaboración y aplicación de códigos éticos en materia de comunicación social y publicidad, inspirados en el bien común y orientados al desarrollo integral del hombre. Estos códigos se hacen especialmente necesarios en el contexto de la televisión, que permite que las imágenes entren en los hogares, allí donde los niños se encuentran a su aire y sin vigilancia. El autocontrol es siempre el mejor control, así como la autodisciplina, en el seno de los propios medios, es la primera y más deseable de las líneas de defensa contra quienes buscan provecho mediante la producción de programas pornográficos y violentos que envilecen los medios de comunicación y corrompen la sociedad misma.

Se urge vivamente a los comunicadores a que, también a través de estos medios, hagan conocer las medidas necesarias que pongan un dique a la marea de la pornografía y de la exaltación de la violencia en la sociedad.

24. Padres. Se invita a los padres a que multipliquen sus esfuerzos en orden una completa formación moral de niños y jóvenes. La cual supone una educación en favor de una actitud sana hacia la sexualidad humana, basada en el respeto a la dignidad de la persona como hija de Dios, en la virtud de la castidad y en la práctica de la autodisciplina. Una vida familiar equilibrada, en la que los padres sean fieles practicantes y totalmente entregados el uno al otro y a sus hijos, constituirá la escuela ideal para la formación a los sanos valores morales.
Los niños y jóvenes de nuestro tiempo necesitan la educación que les permita discernir los programas y madurar en su condición de usuarios responsables de la comunicación. El ejemplo de los padres es determinante en esta materia. La pasividad o autoindulgencia de cara a ciertos programas será fuente de malentendidos perjudiciales para la juventud. Hay que dar especial importanciapara el bien de los jóvenes- al ejemplo de los padres en lo que concierne a la autenticidad de su amor y a la ternura que sepan manifestar en su vida matrimonial; así como a su disponibilidad a discutir con los hijos las cuestiones de interés, en una atmósfera amable y afectuosa. Conviene no olvidar que, cuando se está educando, "se obtiene más con una explicación que prohibiendo" .6

25. EdUCADORES. Los principales colaboradores de los padres, en la formación moral de los jóvenes, son los educadores. Las escuelas y los programas educativos han de promover e inculcar los valores éticos y sociales, de cara a garantizar la unidad y el sano desarrollo de la familia y de la sociedad.

Los programas de mayor valor serán, en el contexto educativo, aquellos que formen a los jóvenes a una actitud crítica y a una capacidad de discernimiento en el uso de la televisión, de la radio y de los otros medios de comunicación social. De este modo los jóvenes serán también capaces de resistir a las manipulaciones y sabrán luchar contra los hábitos meramente pasivos en la escucha y visión de estos medios.

Hay que subrayar la importancia de que las escuelas sepan poner de relieve el respeto a la persona humana, el valor de la vida familiar y la importancia de la integridad moral personal.

26. JóvENES. Los jóvenes contribuirán a poner muros al avance de la pornografía y la violencia en los medios si saben responder, positivamente, a las iniciativas de sus padres y educadores y asumir sus responsabilidades en lo que reclama capacidad de decisión moral, así como en la elección de sus diversiones.

27. EL PúBLICo. El público en general debe también hacer oír su voz. Los ciudadanos -incluidos los jóvenes - tienen la tarea de expresar individual y colectivamente su punto de vista respecto a productores, intereses comerciales y autoridades civiles. Se hace urgente mantener un diálogo continuado entre los comunicadores y los representantes del público, a fin de que quienes actúan en las comunicaciones sociales estén al corriente de las exigencias reales e intereses de los usuarios.

28. AUTORIDAD PÚBLICA. Los legisladores, los encargados de la administración del Estado y de la justicia están llamados a dar una respuesta al problema de la pornografía y de la violencia sádica difundidas por los medios de comunicación. Se han de promulgar leyes sanas, se han de clarificar las ambiguas y se han de reforzar las leyes que ya existen.

Dadas las implicaciones internacionales que presentan la producción y distribución de material pornográfico, hay que actuar 
a nivel regional, continental e internacional de cara a controlar con éxito este insidioso tráfico. Quienes han tomado ya iniciativas de este tipo merecen todo nuestro apoyo y estímulo.?

Las leyes y los agentes de la ley tienen el deber sagrado de proteger el bien común, especialmente el que concierne a la juventud y a los miembros más vulnerables de la comunidad.

Ya hemos señalado algunos de los efectos negativos de la pornografía y la violencia. Cabe sacar también la conclusión de que se pone en tela de juicio y amenaza el bien común especialmente cuando este material se produce, expone y distribuye sin restricciones ni reglamentos.

La autoridad civil está obligada a emprender una rápida acción de cara al problema, allí donde exista, y a emanar criterios preventivos en donde la cuestión comience a plantearse o todavía no haya llegado a ser angustiosa y urgente.

29. IGLESIA Y GRUPOS RELIGIOSOS. La primera responsabilidad de la Iglesia consiste en la enseñanza constante y clara de la fe y, asimismo, de la verdad moral objetiva, incluidas aquellas verdades referentes a la moral sexual. Una era de permisividad y de confusión moral como la nuestra pide que la voz de la Iglesia sea profética, lo que la hará aparecer a menudo como signo de contradicción.

La llamada "ética" de la gratificación individual inmediata se opone fundamentalmente a la realización plena e integral de la persona humana. La educación a la vida familiar y a la inserción responsable en la vida social exige la formación a la castidad y la autodisciplina.

La pornografía y la violencia generalizada tienden a ofuscar la imagen divina en cada persona humana, debilitan el matrimonio y la vida familiar y dañan gravemente a los individuos y a la sociedad.

En donde sea posible, la Iglesia está llamada a colaborar con otras Iglesias cristianas, comunidades y grupos religiosos a fin de enseñar y promover este mensaje. Debe igualmente empeñar a sus personas e instituciones en una acción formativa al uso de los medios de comunicación social y su papel en la vida individual y social. En este campo los padres merecen una asistencia y atención especial.

Por estos motivos, la formación a la comunicación debiera ser parte de los programas educativos de las escuelas católicas y de otras iniciativas educativas de la Iglesia, así como en la formación en los seminarios. ${ }^{8}$ Cabe decir lo mismo para los programas de formación de religiosos y religiosas y de los miembros de los institutos seculares, así como para la formación permanente del clero y la catequesis parroquial de jóvenes y adultos. Tanto sacerdotes como religiosos y religiosas que trabajan en la educación pastoral debieran comenzar por ellos mismos dando ejemplo de discernimiento en medios escritos y audiovisuales.

30. Por último, una actitud de pura restricción o de censura por parte de la Iglesia de cara a estos medios no resulta ni suficiente ni apropiada. La iglesia tiene, al contrario, que iniciar un diálogo continuo con los comunicadores conscientes de sus responsabili- dades. Debe animarles y sostenerles en su misión allí donde sea posible y deseable. Los comunicadores católicos y sus organizaciones, con sus perspectivas y experiencias propias, están llamados a jugar un papel decisivo en tales conversaciones.

31. La crítica y las organizaciones católicas, al evaluar concienzudamente las producciones y publicaciones en función de criterios morales claros y substanciales, ofrecen una valiosa asistencia a los profesionales de la comunicación y a las familias. Asimismo, las orientaciones que ofrecen los documentos ya existentes sobre comunicación social -incluidas las recientes tomas de posición de numerosos obispos sobre la pornografía y la violencia-merecen ser cuidadosamente estudiadas y objeto de aplicación sistemática.

32. El presente documento quiere ser una respuesta a las preocupaciones ampliamente expresadas por familias y pastores de la Iglesia, a quienes se invita a una reflexión - de carácter ético y práctico- cada vez más amplia acerca del problema de la pornografía y la violencia en los medios de comunicación social. Al tiempo que se anima a todos a poner en práctica la advertencia de San Pablo: "No te dejes vencer por el mal; antes bien, vence el mal con el bien" (Rom 12, 21).

Consejo Pontificio para las Comunicaciones Sociales Ciudad del Vaticano, 7 de mayo de 1989

XXIII Jornada Mundial de las Comunicaciones Sociales.

$$
\begin{gathered}
\text { †JOHn P. Foley } \\
\text { Presidente } \\
\text { MOns. PIERFRanco PAStORE } \\
\text { Secretario }
\end{gathered}
$$

1 Communio et progressio, 22

2 Sollicitudo rei socialis, 26.

3 Inter mirifica, $2^{\text {a }}$.

4 Familiaris consortio, 76; cf. Mensaje de JUAN PABLO II para la Jornada Mundial de las Comunicaciones Sociales, 1 de mayo de 1980.

5 Entre ellos cabe citar: 1) II rapporto Longford sulla Pornografía (título original, Pornography: The Longford Report), Ricerche Musia, Milán (Italia), 1978;2) Final Report of the Attorney General's Commission on Pornography, Rutledge Hull Press, Nashville, Tennesseen (USA), 1986; 3) ISPES (Istituto di Studi Politici, Economici e Sociali), I e II Rapporto sulla Pornografía in Italia, Roma (Italia), 1986 y 1988.

6 Communio et progressio, 67.

7 La CEE (Comunidad Económica Europea), el Consejo de Europa y la UNESCO, entre otras organizaciones, están actuando en este sentido.

8 Cf. Congregación para la educacion catolica, Orientaciones para la formación de los futuros sacerdotes en los medios de comunicación social, Ciudad del Vaticano, 1986. 